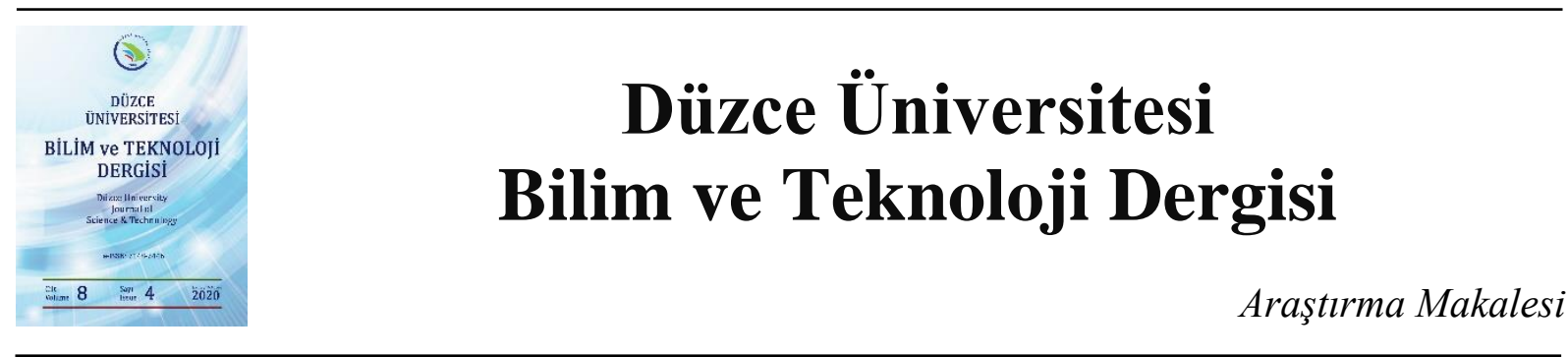

\section{Yangın Tüpünün İç Basınç Altındaki Davranışının Deneysel ve Nümerik Olarak İncelenmesi}

\author{
Ersin TOPTAŞ ${ }^{\mathrm{a}, ~ *}$ \\ ${ }^{a}$ Mekatronik Müh. Bölümü, Teknoloji Fakültesi, Marmara Üniversitesi, İstanbul, TÜRKIYE \\ Sorumlu yazarın e-posta adresi: etoptas@marmara.edu.tr
}

DOI: 10.29130/dubited.731650

\begin{abstract}
ÖZET
$\mathrm{Bu}$ çalışmada, araçlarda kullanılan yangın söndürücü tüplerin iç basınç altında yapısında meydana gelen mekanik davranışları incelendi. Bu amaç için bir deneysel düzenek tasarlanarak tüplerin iç basınç testleri gerçekleștirildi. Kurulan deney düzeneğinde, uygulanan iç basınç değerinin tüpün yırtılarak patlaması sonucunda tüpün etrafina yerleştirilen deformasyon ölçerler (strain gauge) vasıtasıyla ölçümler yapılmıştır. Ayrıca yapılan bu çalışma $\mathrm{NX} /$ Nastran programında yapılan SEA analizi ile desteklendi. İç basınç testinde çok yaygın kullanılan $1 \mathrm{~kg}$ 'llk yangın tüpün 92 bar civarında tüp yarılarak patlamış ve patlama anına kadar tüpteki deformasyonlar incelenmiştir. Deformasyon sonuçlarına göre çevresel gerilmelerin daha büyük önem arz ettiği görüldü. Bu sayede yangın söndürmede kullanılan ve hayati önem taşıyan bu ürünlerin iç basınç altında ortaya koydukları mukavemet performansı incelendi. Bu tüplerin mekanik davranışlarının anlaşılmasıyla yapılacak tasarım ve imalat değişkenleriyle aynı hacimlere daha yüksek kütleleri ihtiva eden yangın tüplerinin üretilmesi açısından önemlidir.
\end{abstract}

Anahtar Kelimeler: Yangın tüpü, Basınçlı tüp, Yüksek Basınç, Sonlu Elemanlar Analizi

\section{Experimental and Numerical Investigation of Fire Tube Behavior Under Internal Pressure}

\begin{abstract}
In this study, the mechanical behaviors of the fire extinguisher tubes used in vehicles under the internal pressure were examined. For this purpose, an experimental setup was designed and internal pressure tests of the tubes were carried out. In the experiment set up, strain gauge measurements were made around the tube as a result of the tearing of the applied internal pressure value and the tube bursting. In addition, this study was supported by FEM analysis in NX / Nastran program. In the internal pressure test, $92 \mathrm{~kg}$ of $1 \mathrm{~kg}$ fire tube, which is widely used, burst by breaking the tube and deformations were examined until the moment of the explosion. According to the deformation results, environmental stresses were found to be of greater importance. In this way, the strength performance of these products, which are used in fire extinguishing and are of vital importance, were examined. It is important for the production of fire tubes containing higher masses with the same volumes as the design and manufacturing variables to be made by understanding the mechanical behavior of these tubes.
\end{abstract}

Keywords: Fire tube, Pressure tube, High Pressure, Finite Element Analysis

Geliş: 04/05/2020, Düzeltme: 13/08/2020, Kabul: 02/09/2020 


\section{GIRIS}

Araçlarda olası bir yangında ilk kullanılacak en etkili yardımcı söndürücü araç yangın tüpüdür. Yangın tüpleri hayatımızın her alanında yer almakta olup araçlarımızda taşınması da zorunluluktur. Bu yangın tüpleri içerisindeki söndürücü bileşenler kuru kimyevi toz, köpük veya halokarbon olarak kullanılabilmektedir. Bu türler tüplerin içerisine bu maddeler belirli bir basınçla basılmaktadır. Tüpün içerisinde kullanılan yangın söndürücünü türü ne kadar çok basınca çıkartılırsa miktarı da artırılmış olmaktadır. Bu sebeple kullanılan tüplerin malzemesi, tasarımı, imalatı, kullanılan kaynak biçimi, iç basınç değeri, ortam sıcaklı̆̆ gibi birçok parametrenin önemi büyüktür. 29 Mayıs 2002 tarihinden üye ülkelerin 97/23/EC basınçl1 ekipmanlar yönetmeliği ve TS EN 13445-4'ye göre yangın tüpleri basınçlı kap olup $0.49 \times 10^{5} \mathrm{~Pa}(0.5$ bar) ve daha yüksek basınçlı sıvı ve gazların depolandığı kaplardır. Araçlarda kullanılan yangın tüpleri iç basınç değeri 1 bar ve üzerinden olmasından dolayı yüksek basınç olarak değerlendirilmektedir [1-3].

Yangın tüpleri yüksek basınçla çalışan ekipmanları olması sebebiyle bu tüplerin mekanik davranışları büyük riskler içermektedir. Basınçlı tüplerin kullanım biçimi, tasarım hataları, malzeme dayanımlarının azalması gibi durumlar tüpün iç basıncın etkisiyle Şekil 1'de gösterildiği gibi patlayarak tüpün eksenel yönde yırtılabilmektedir [4]. Bu sebeple bu tür tüpler, araçlarda veya canlıların bulunduğu ortamda olması sebebiyle tehlike arz etmekte olup bu tür basınçlı tüplerin dikkatli tasarlanması ve üretilmesi gerekmektedir.

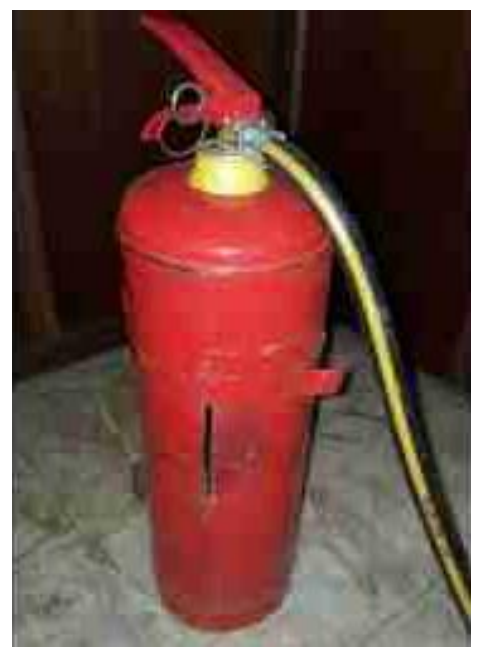

Şekil 1. Yangin tüpünün patlama sonrası şekli [5].

Yangın tüplerinin yangın söndürme sırasında uzun süre kullanımı açısından içerisindeki söndürücü bileşenin miktarı önemlidir. Bu miktarın artırılması tüp içerisindeki basınç değerinin artmasına ve bununla birlikte kullanılan tüpün daha mukavemetli olması gerekmektedir. Zira bu tüpler basınçlı kaplar olması sebebiyle içerisindeki basınç, kap çeperlerine her yönden basıncı aynı oranda iletmektedir ve çeperde gerilmelere maruz bırakmaktadır. Silindirik basınçlı kaplar, literatürde ince ve kalın cidarlı olmak üzere iki gruba ayırmaktadır. Basınçlı kaplarda silindirin iç çapı (r) ve cidar kalınlığı (t) arasındaki $r / t \geq 10$ oranına göre kabın ince cidarlı olup olmadığ 1 kabul edilmektedir $[3,6]$. Yangın tüplerin dış çap ve et kalınlığı sebebiyle ince cidarlı yüksek basınçlı tüpler olarak belirtebiliriz. Bu sebeple bu çalışmada ince cidarlı yangın söndürücü tüplerin iç basınç altındaki mekanik davranışlarının analitik ve deneysel yöntemle irdelenmesi hedeflenmiştir. 


\section{MATERYAL ve METOT}

Yangın tüplerin iç basınç altındaki mekanik davranışlarının incelenmesi analitik, simülasyon ve deneysel çalışmalarla yürütüldü. Bu çalışmada otomobil araçlarında daha çok kullanılan 1 kg'lık kuru kimyevi ihtiva eden yangın tüpü seçildi. Bu tüp dış çapı $90 \mathrm{~mm}$ ve et kalınlığı $1 \mathrm{~mm}$ olup teknik ölçüleri şekil 2'de görüldüğü gibidir.
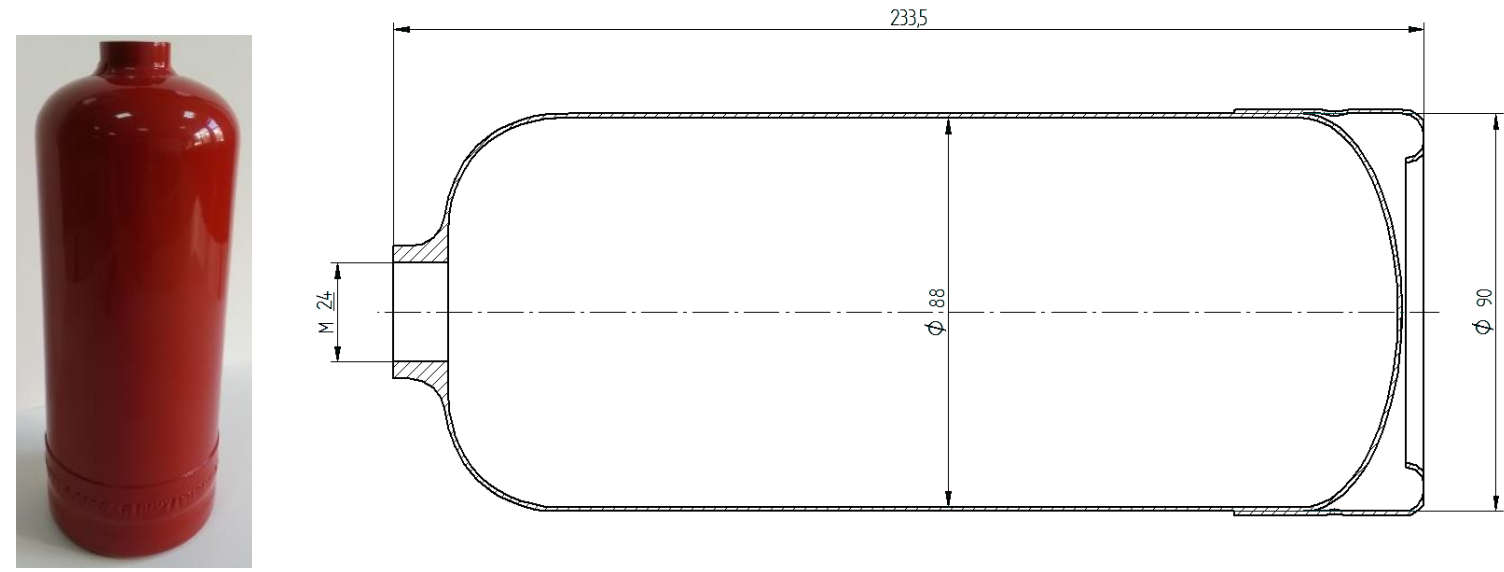

Şekil 2. 1 kg'lık yangın tüpü a) Genel şekli b) Geometrik ölçüleri

Şekil 2'de verilen 1 kg'lık tüpün iç basınç altındaki mekanik davranışlarının ölçülmesi için test düzeneği oluşturuldu. Bu test düzeneği Şekil 3'de gösterildiği gibi yangın tüpü, yüksek basınç test pompası, tüp üzerinde deformasyon ölçerler (strain gauge), verilerin toplanmasını sağlayan ölçüm sisteminden oluşmaktadır. Bu ölçüm sistemi tüpe uygulanan iç basınç değeri ile birlikte tüp üzerinde oluşan deformasyonların aynı anda verileri tarayarak bilgisayara aktarmaktadır.

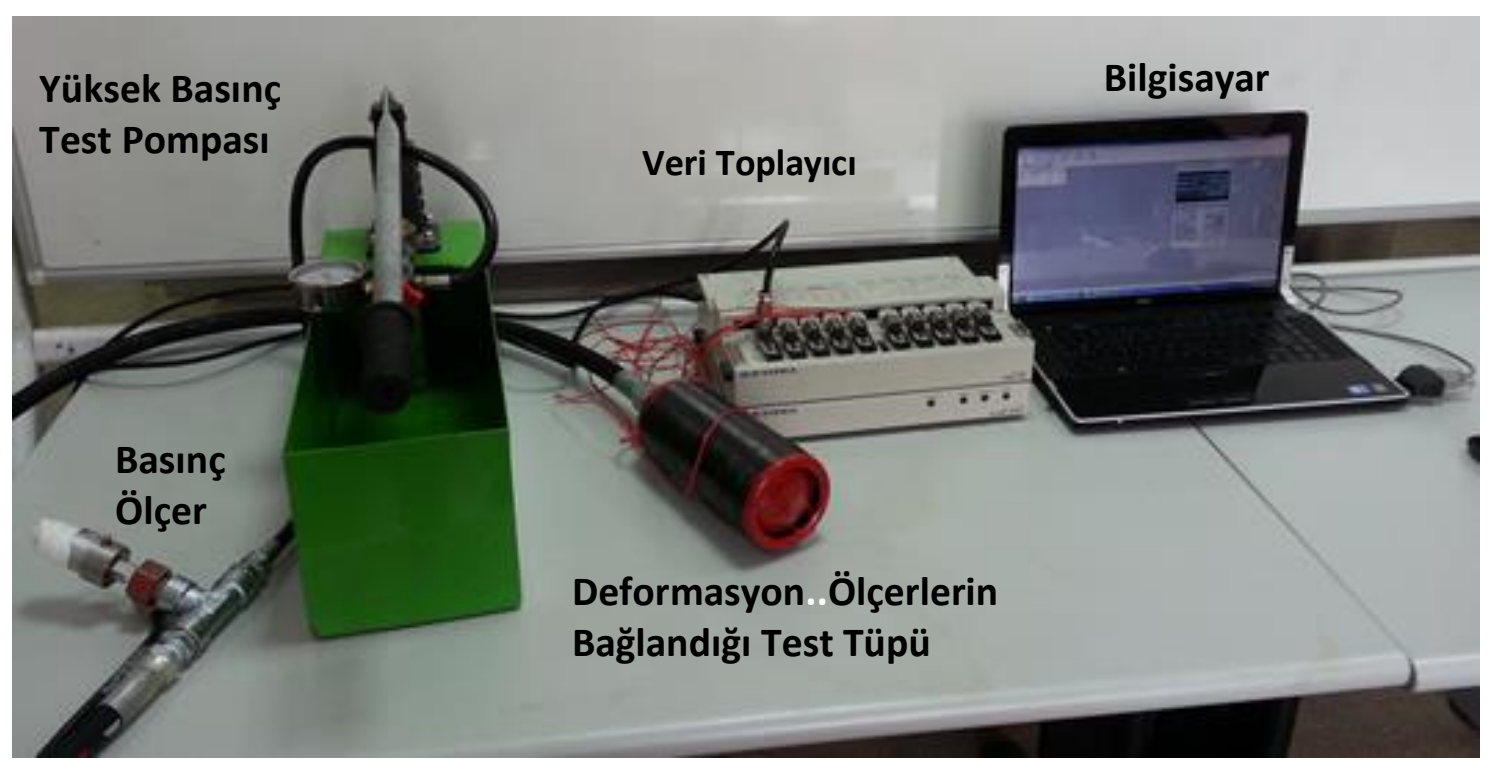

Şekil 3. Yüksek basınç test düzeneği.

Suyun iç basın malzemesi olarak kullanılmasıyla yüksek basıç̧lara ulaştırmak amacıyla test düzeneğinde el ile kontrol edilen yüksek basınç su pompası kullanılmıştır (Şekil 3). Bu yüksek basınçlı test su pompası ile azami $12 \mathrm{MPa}$ (120 bar) basınç oluşturulabilmektedir. Yüksek iç basınç altında yangın tüpün mekanik davranışlarının ölçümünde deformasyon ölçerler (strain gage) kullanılmıştır. Bu deformasyon ölçerler Kyowa marka 120 ohm'luk deformasyon ölçer olup, suyun iç basıncının ölçülmesinde de yine Kyowa marka basınçölçer kullanılmıştır. Bu deformasyon ölçer ve basınç ölçerden 
gelen verilerin toplanması ve anlamlı hale getirilmesinde Kyowa veri toplayıcısı kullanılarak veriler elde edilmiştir.

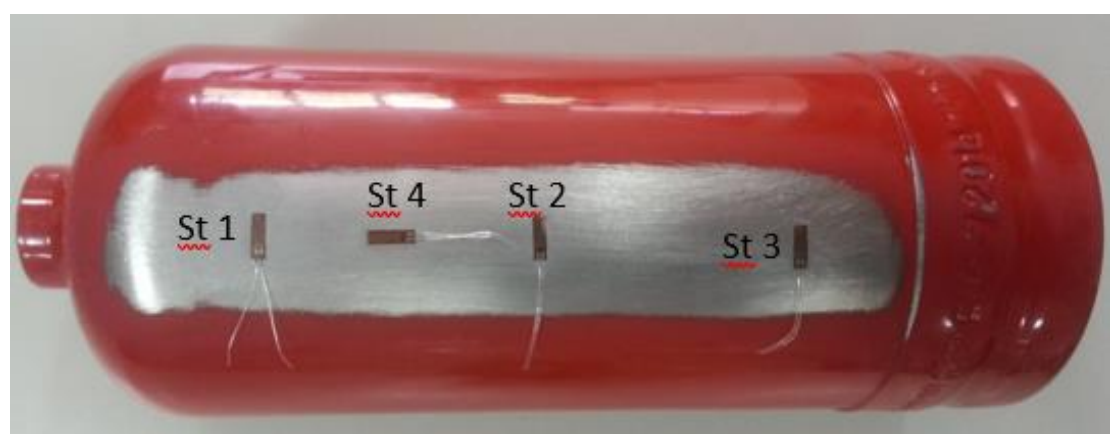

Şekil 4. Deformasyon ölçerlerin yapıştırılma yönleri

Tüp üzerindeki mekanik davranışların ölçülmesi ve incelenmesi için yapıştırılan derformasyon ölçerler Şekil 4'de görüldüğü gibi farklı yönde ve yerde olmak üzere toplamda dört adet yapıștırılmıştır. Tüpün yüksek basınç altında yapılan testler Şekil 5 'de görüldüğü gibi yüksek basıncın tehlikeli olabilecek koşullara uygun olacak şekilde tedbirler altında testler gerçekleştirildi. Yapılan testlerde su basınç manuel olarak test pompası ile basınç değeri 3 dakika sürecek şekilde tüpün patlamasına kadar sürdürüldü.

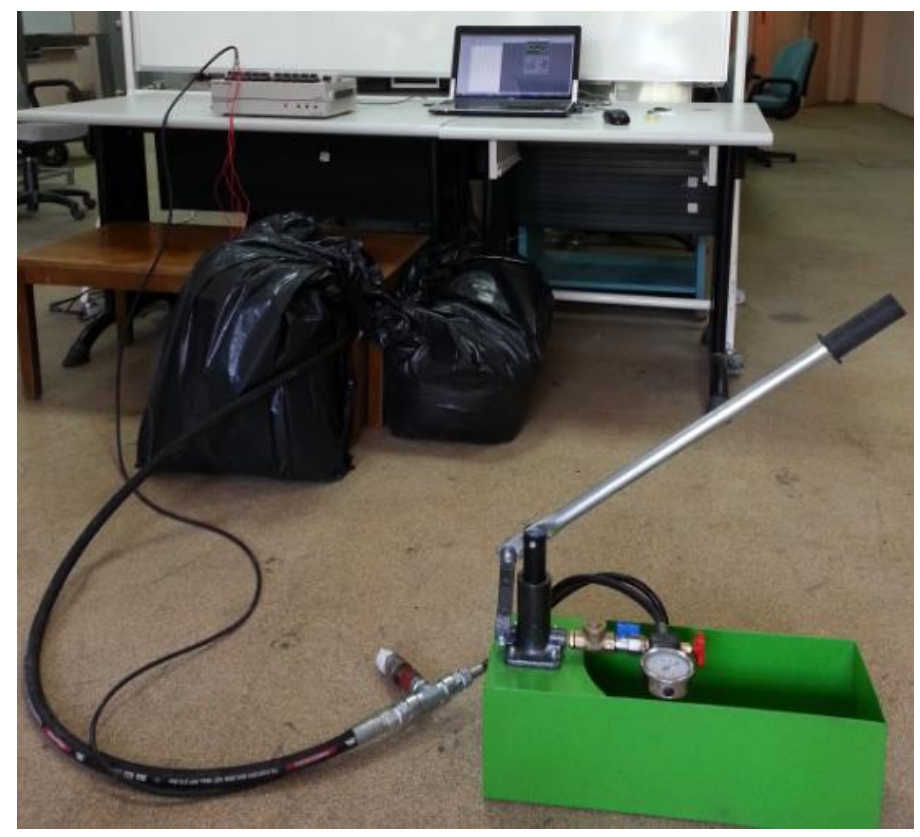

Şekil 5.Yüksek basınç test düzeneğinde deney koşulları.

Yangın tüplerin ince cidarlı ve yüksek basınç altında oluşan eksenel ve çevresel(radyal) gerilmeler analitik olarak hesaplanabilmektedir. Çevresel gerilmeler $\sigma_{1}$ eksenel gerilmeden $\sigma_{2}$ iki katı olup tüplerin gövdelerinden yarılarak patlamaya sebebiyet veren bir durumdur. Bu sebeple iç basınç altındaki ince cidarlı tüplerin gerilmeleri Denklem 1 ve 2 de verildiği hesaplanabilmektedir [7-10]. 


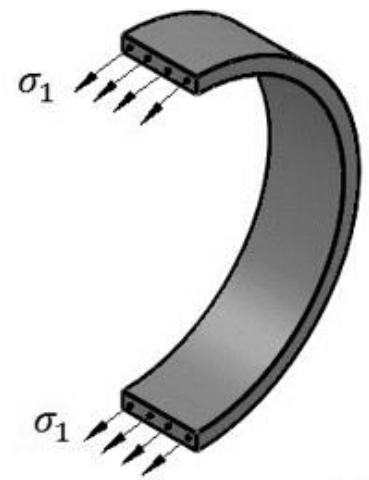

a)

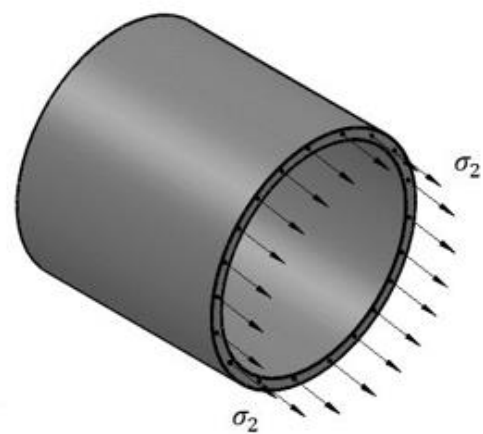

b)

Şekil 6. Basınçlı kaplarda oluşan gerilmeler a) Çevrelsel Gerilme b) Eksenel Gerilme [7].

$$
\begin{gathered}
\sigma_{1}=\frac{P r}{t} \\
\sigma_{2}=\frac{P r}{2 t}
\end{gathered}
$$

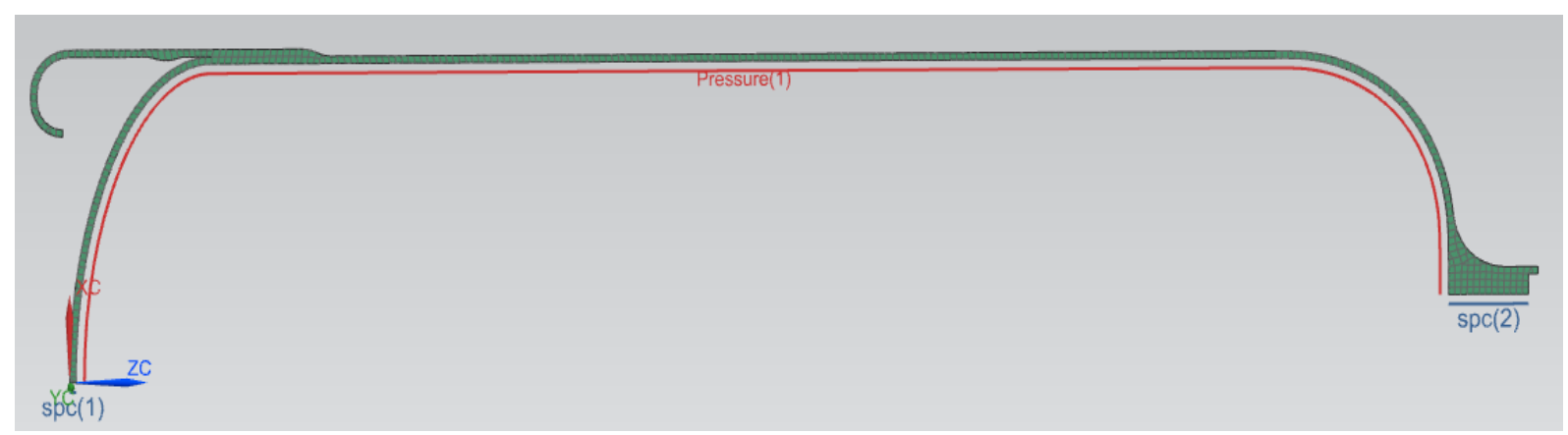

Şekil 6. Tüpün aksisimetrik sonlu elemanlar modeli.

Mekanik testi yapılan 1 kg'lık yangın tüpün bilgisayar modeli yapılarak sonlu elemanlar analizi (SEA) gerçekleştirildi. Analizde modelin katı model olarak değil aksisimetrik modeli oluşturularak SEA gerçekleştirildi (Şekil 6). Modelin iç basınç değeri $7 \mathrm{MPa}$ olacak şekilde uygulanmıştır. Oluşturulan SEA modelinde 398 element ve 1835 node kullanılarak analiz gerçekleştirildi.

\section{BULGULAR ve DEGERLENDİRME}

Yangın tüpün içine basılan su basıncı ile yapılan yüksek basınç testi tüpün patlamasına kadar yapıldı. Tüpün uygulanan iç basınç testinde azami uygulanan basın değeri 92 bar olarak ölçülmüştür. Bu değer tüpün imalatçı firmasından alınan 90 bar civarlarında patladığı bilgisini doğrulamaktadır. Tüpün patlaması sonucunda meydana gelen deformasyonu Şekil 7'de görüldüğü gibidir. Şekil 7'de görüldüğü gibi tüpün karın kısmında yırtılmak suretiyle ikiye ayrıldığı görülmektedir. 


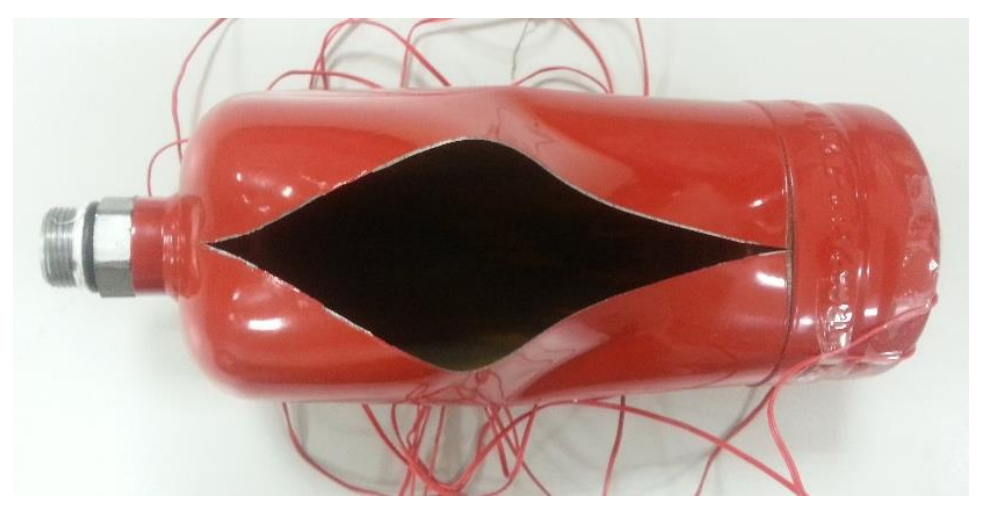

Şekil 7. Tüpün yüksek basınç testinde patladıktan sonraki deformasyonu.

Yangın tüpün yapılan deneysel testinde bağlanan dört deformasyon ölçerden alınan birim şekil değişimlerinin uygulanan basınç altındaki sonuçları Şekil 8'de verilmiştir. Elde edilen veriler incelendiğinde St4 eksenel diğer üç deformasyon ölçer ise çevresel şekil değişimleri ölçmüştür. Elde edilen veriler 1şığında eksenel deformasyon değerleri diğerlerinden oldukça düşüktür. Bu durum ince cidarlı basınçlı tüplerde çevresel gerilmelerin daha fazla olduğunu göstermektedir. Diğer üç çevresel deformasyon şekil değişimleri en büyükten en küçüğe göre St1, St2 ve St3 olarak sıralanmaktadır. Bu veriler bize tüpteki patlama St3'ün olduğu yerden başlayıp Stl'in olduğu yere kadar devam ettiğini göstermektedir.

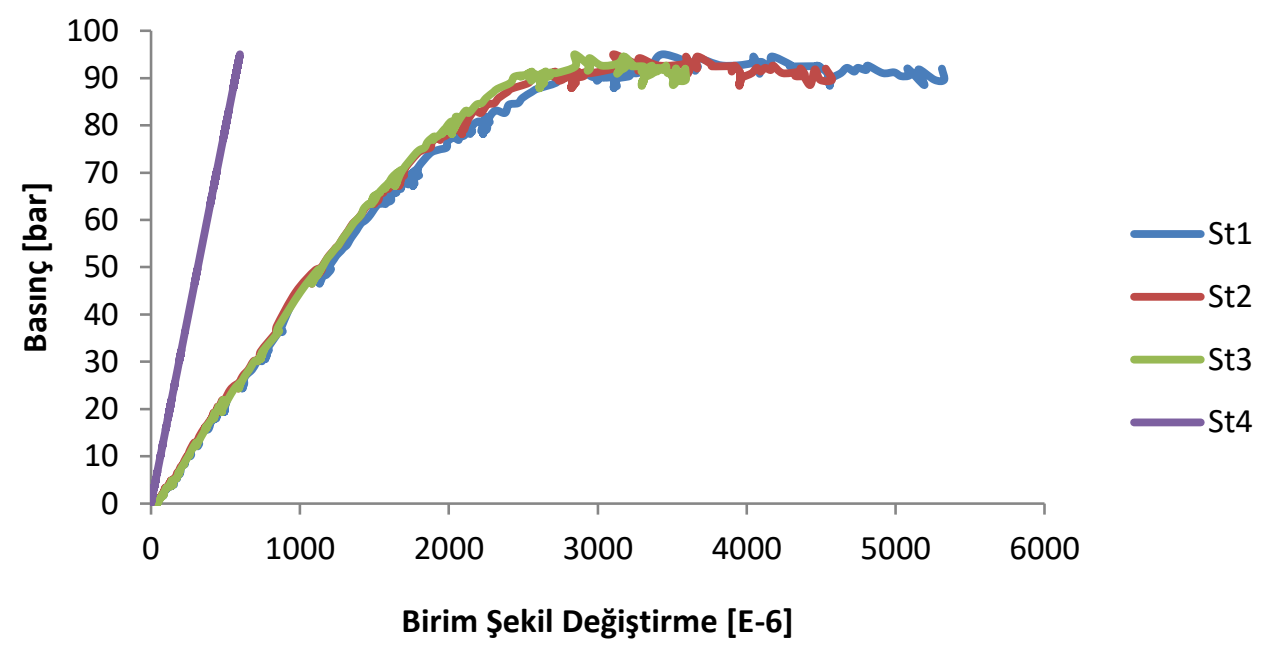

Şekil 8. Tüpün yüksek basınç testinde patladıktan sonraki deformasyonu.

Ayrıca Şekil 8 dikkatli incelendiğinde çevresel şekil değişim değerleri yaklaşık 70 bar civarına kadar doğrusal hareket eder iken daha sonra doğrusal olmaktan çıkmaktadır. Buda tüpün 70 bar civarlarından sonra tüpün malzemesi olan çeliğin akma değerini bize göstermektedir. Bu akma bölgesinden sonra tüp plastik deformasyon bölgesinde azami değerine ulaşarak patlama meydana gelmiştir. $\mathrm{Bu}$ akma bölgesinde oluşan çevresel deformasyon $1500 \mu \varepsilon$ olarak ölçüldü.

Tüpe uygulanan iç basınç değerinde akma gerilmesi bölgesinde ki basınç değeri olan $70 \mathrm{MPa}$ değeri alınarak denklem 1'de verilen formül yazıldığında meydana gerilme analitik olarak $315 \mathrm{MPa}$ olarak hesaplana bilmektedir. $\mathrm{Bu}$ elde edilen gerilme elastik bölgede geçerli olan Hooke kanuna göre incelediğinde $1500 \mu \varepsilon$ akma bölgesindeki birim şekil değişimiyle ortaya çıkan malzemenin elastik modülünü $210 \mathrm{GPa}$ olarak hesaplanmaktadır. Bu hesaplanan elastik modül değerinin yangın tüp üreticisinin sunduğu çelik malzemesini doğrulamakta ve yapılan testi de onaylanmasını sağlamaktadır. 


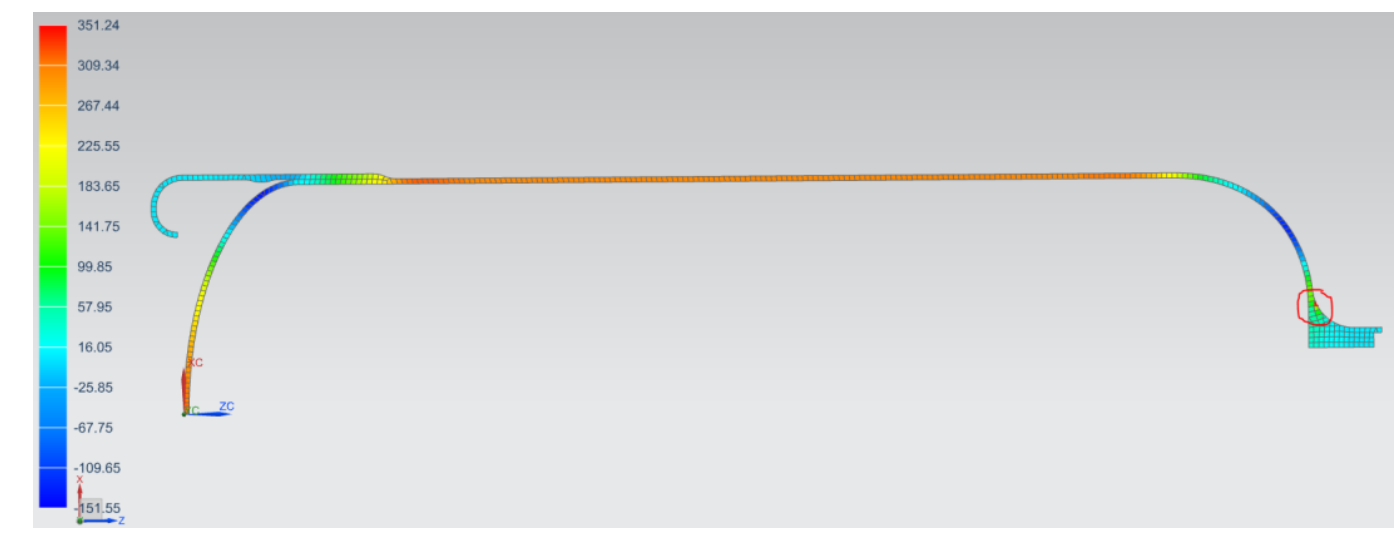

Şekil 9. Yangı tüpün aksisimetrik SEA sonucu.

Ayrıca yangın tüpün yapılan aksisimetrik sonlu elemanlar modellemesinde yapılan iç basınç test sonuçlarının tüpün patlama bölgesindeki değerlerin $308 \mathrm{MPa}$ olarak hesaplandı (Şekil 9). Ama simülasyon soncunda meydana gelen maksimum gerilmelerin bu geometri için tüpün boğaz kısmındaki en küçük alan bölgesinde oldu ve bu değerinde $351 \mathrm{MPa}$ civarında olduğu görüldü. Tüpün bu bölgede patlamamasının sebebi olarak tüpün plastik deformasyon bölgesinde tüpün göbeğinde meydana gelen aşırı deformasyon sonucudur. Ayrıca SEA ile deneysel verilerin kıyaslanmasında Şekil 10'da karşılaştırmalı verilmiştir. Bu karşılaştırma SEA deki uygulanan $7 \mathrm{MPa}$ iç basınç altındaki element birim şekilde değişimleri, deneysel olarak yapılan testteki deformasyon ölçerlerden alınan veriler ile kıyaslanmıştır.

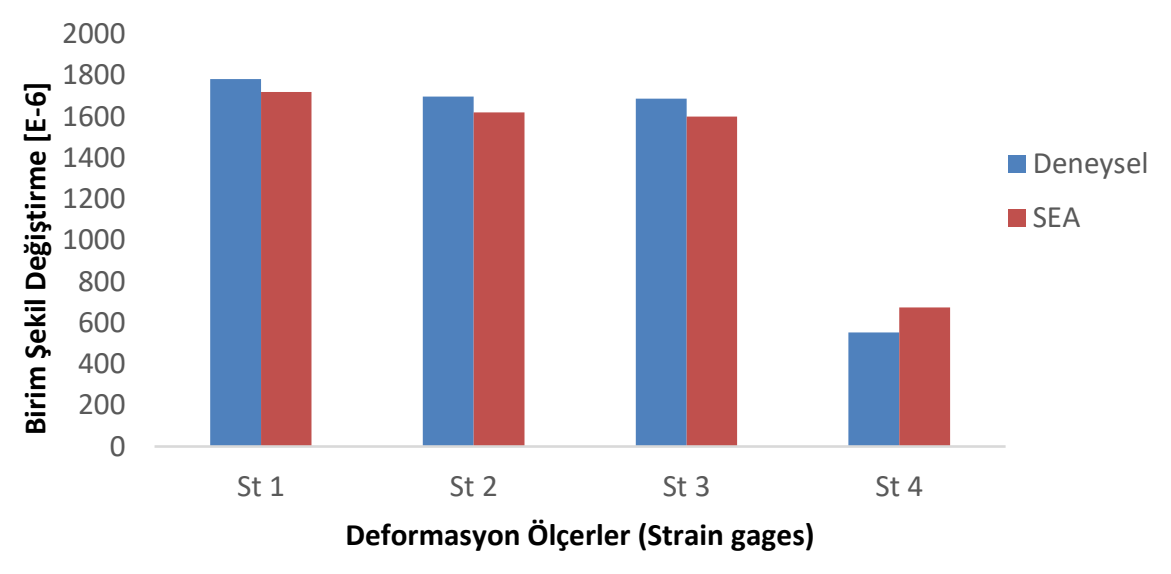

Şekil 10. Tüpün deneysel ve nümerik karşılaştırması

\section{IV.SONUC}

Araçlarda kullanılan 1 kg'lık yangın tüpünün, iç basınç altında patlatılıncaya kadar yapılan yüksek basınç testinde mekanik davranışlarının analitik, simülasyon ve gerçek test sonuçları elde edildi. Bu test sonuçlarına göre bu tür tüpler verilen geometrik bilgilere göre ince cidarlı tüp olması ve iç basınç değerinden dolayı yüksek basınçlı tüpler kategorisindedir. Bu tür tüpler araçlarda çok sık kullanıldığından bu tüplerin güvenlik açısından tasarımları, kullanılan malzeme ve imalatı açısından önem arz etmektedir. Yapılan deneysel test sonucu bu tür yüksek basınçlı ince cidarlı tüpler çevresel gerilmelerin fazla olduğu karın bölgesinden yırtılarak patlamaktadır. Ayrıca SEA ile yapılan simülasyon sonucunda bu tür tüplerin boğaz bölgesindeki geometrilerinde önemli olduğunu göstermektedir. $\mathrm{Bu}$ sebeple bu tür tüplerin TS EN 13445-4'ye göre güvenlik faktörü göz önüne alınarak 25 bardan fazla basınç yüklemesi yapılmaması önemlidir. 
Eğer bu tür tüplerde yangın söndürücü madde miktarının artırılması durumunda tüp cidarının artırılması veya tüpün çevresel olarak sarılabilen cam, karbon gibi sürekli elyaf ile sarılma işlemi ile güçlendirilebilir [11]. Tüpün ağırlık ve yüksek dayanım göstermesi istendiği durumda tüp karbon elyaf takviyeli reçine ile elyaf sarma işlemi iyi bir sonuç ortaya koyacaktır.

\section{KAYNAKLAR}

[1] F. Mestan, "Basınçlı kapların deneysel ve teorik olarak incelenmesi," Yüksek lisans tezi, Havacılık ve Uzay Teknolojileri Enstitüsü, Hava Harp Okulu Komutanlığı, İstanbul, Türkiye, 2010.

[2] E. Koç,İ. Keleş, K. Yıldızlı, İnce cidarli silindirde gerilme ve şekil değiştirme analizi deneyi, Ders Notları, Ondokuz Mayıs Üniversitesi Makine Mühendisliği, Samsun, Türkiye, 2012.

[3] D. Roylance, Pressure Vessels, Lecture Notes, Department of Materials Science and Engineering," Massachusetts Institute of Technology, Cambridge, 2001.

[4] E. Toptaş, ve N. Akkuş. "Damage detection of carbon fibers in filament winding machines using an electrical resistance method," The International Journal of Advanced Manufacturing Technology, c. 93, ss. 671-679, 2017.

[5] Yangın söndürme tüpü patladı televizyon parçalandı, Hürriyet Gazetesi (2016), [Çevrimiçi]. Erişim Adresi: https://www.hurriyet.com.tr/yangin-sondurme-tupu-patladi-televizyon-parcala40275056. Erişim Tarihi: 14 Nisan 2020.

[6] F. Beer, R.E. Johnston, Ö. Akgün, O. Yazıcıoğlu, T. Kotil, Cisimlerin Mukavemeti, Beta Yayın, 2003.

[7] N. Akkuş, E. Toptas, Ö. Topal, "Thermomechanical Analysis of Arc Welded Joint by Finite Element Method," International Congress on Advances in Welding Science and Technology for Construction, Energy and Transportation Systems (AWST - 2011), 2011.

[8] E. S. Erdiller, "Experimental Investigation for Mechanical Properties of Filament Wound Composite Tubes," M.S. thesis, Mechanical Engineering, The Graduate School Of Natural And Applied Sciences, Middle East Technical University, Ankara, Turkey, 2004.

[9] A. Önder, "First Failure Pressure of Composite Pressure Vessels," M.S. thesis, Graduate School of Natural and Applied Sciences, Dokuz Eylül University, İzmir, Turkey, 2007.

[10] E. Toptaş, "Şekil Hafizalı Metaller İle Aktüatör Tasarımı," Yüksek lisans tezi, Makine Eğitimi Anabilim Dalı, Fen Bilimleri Enstitüsü, Marmara Üniversitesi, İstanbul, Türkiye, 2006

[11] T. Hwang, J. Park, H. Kim, "Evaluation of Fiber Material Properties in Filament-Wound Composite Pressure Vessels," Composites Part A: Applied Science and Manufacturing, c. 43 s. 9, ss. 1467-1475, 2012. 